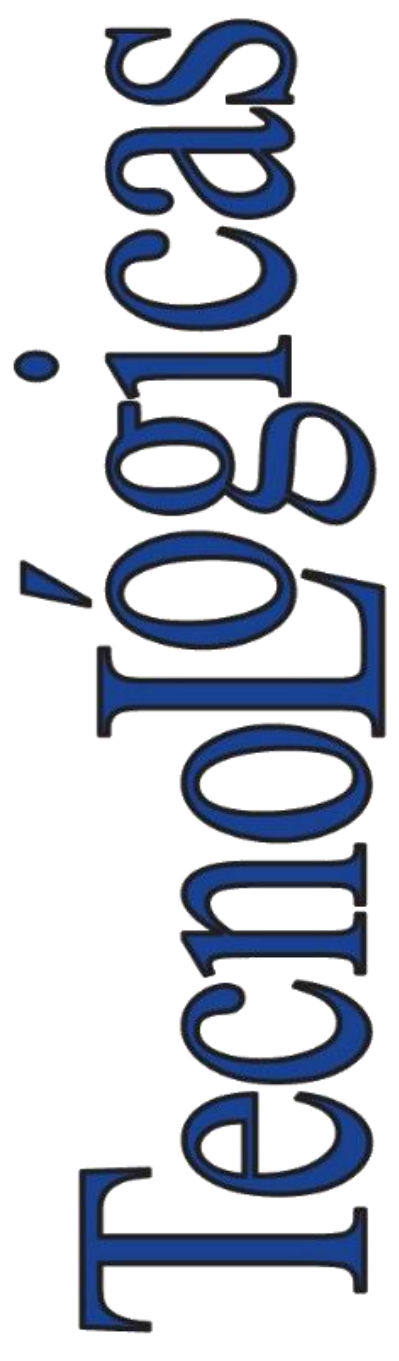

ISSN-p: 0123-7799 ISSN-e: $2256-5337$

Vol. 24, nro. 52, e1939, 2021

Recibido: 18 marzo 2021 Aceptado: 8 agosto 2021 Disponible: 8 septiembre 2021

CInstituto Tecnológico Metropolitano

Este trabajo está licenciado bajo una Licencia Internacional

Creative Commons Atribución (CC BY-NC-SA)

\section{Realidad aumentada como alternativa didáctica en escuelas públicas en zonas rurales y semiurbanas de San Quintín y Mexicali, México}

\section{Augmented Reality as a Didactic Alternative in Public Schools in Rural and Semi-Urban Areas in San Quintín and Mexicali, Mexico}

\author{
(D) Juan Gabriel López-Hernández ${ }^{1}$; \\ (D) Gabriel Alejandro López-Morteo ${ }^{2}$; \\ iD Araceli Celina Justo-López ${ }^{3}$
}

\footnotetext{
${ }^{1}$ Universidad Autónoma de Baja California, Mexicali, México, glopez17@uabc.edu.mx

2 Universidad Autónoma de Baja California, Mexicali, México, galopez@uabc.edu.mx

${ }^{3}$ Universidad Autónoma de Baja California, Mexicali, México, araceli.justo@uabc.edu.mx
}

Cómo citar / How to cite

J. G. López-Hernández; G. A. López-Morteo; A. C. Justo-López, "Realidad aumentada como alternativa didáctica en escuelas públicas en zonas rurales y semiurbanas de San Quintín y Mexicali, México”, TecnoLógicas, vol. 24, nro. 52, e1939, 2021. https://doi.org/10.22430/22565337.1939 


\section{Resumen}

Existe una brecha tecnológica en escuelas rurales y urbanas de San Quintín y Mexicali, el objetivo de este estudio fue establecer las bases de una intervención pedagógica, utilizando recursos que permitieran mayor interacción del estudiante con su propia realidad, a través del uso de tecnología en escuelas de nivel medio y medio-superior en Baja California, que sustenta la propuesta etnometodológica de investigación - acción, apoyándose en el método del Aprendizaje Basado en Problemas de origen constructivista. En este trabajo se diseñó un modelo de realidad aumentada que facilitara dicha intervención didáctica, así como instrumentos para evaluar la percepción por estudiantes y maestros para discutir y analizar sus respuestas con un enfoque mixto. En general, se identificó poca disponibilidad de dispositivos móviles en escuelas rurales, comparadas con la escuela urbana. En la evaluación sobre la percepción que tuvieron estudiantes y maestros sobre su implementación, se obtuvo que la propuesta didáctica induce a la prevención, siendo además considerada una actividad "Fácil", donde hubo mayor preferencia por las representaciones gráficas en 3D en realidad aumentada, y los docentes involucrados coincidieron en que existió "Motivación al diseñar mapa con realidad aumentada", pues "Fomentó la participación en la actividad", "Reafirmación en los valores" y "Potencia en el aprendizaje". El efecto obtenido de incluir la metodología del aprendizaje basado en problemas indujo a los estudiantes a ser sujetos activos en la solución de estos, siendo conscientes de su participación y con orientación a seguir valores preventivos e incluyentes.

\section{Palabras clave}

Realidad aumentada, aprendizaje basado en problemas, tecnologías emergentes, enseñanza pública.

\section{Abstract}

There is a technological gap between rural and semi urban schools in San Quintín and Mexicali (Baja California, Mexico). The objective of this study was to establish the bases of a pedagogical intervention (using augmented reality) that enabled middle and upper-middle school students there to interact more with their own reality. This study applied the ethnomethodological approach known as action research and problem-based learning, which has a constructivist origin. An augmented reality model was designed to facilitate such intervention, and questionnaires were used to evaluate students' and teachers' perceptions of it. Their responses were discussed and analyzed adopting a mixed-methods approach. It was found that, in general, mobile devices are less available in rural schools than in their semi urban counterparts. Students and teachers perceived that the implementation of this didactic intervention fostered disaster prevention and was easy. Most preferred 3D graphic representations in augmented reality, and teachers agreed that it was more motivating to design an augmented reality map because it encouraged participation, reaffirmed values, and promoted learning. Problem-based learning encouraged students to be active subjects who provide solutions, are aware of their participation, and adopt the values of disaster prevention and inclusion.

\section{Keywords}

Augmented Reality, Problem-Based Learning, Emerging Technologies, Public Education. 


\section{INTRODUCCIÓN}

Según trabajo de [1], en intervenciones didácticas en las que se ha empleado a la realidad aumentada (RA) en el sector educativo, se presentan distintos efectos significativos en los educandos, como puede ser el incremento de la retención en la memoria de largo periodo, además de provocar una mayor colaboración entre los estudiantes y mejorar su motivación, de tal manera que, al comparar el aprendizaje entre RA y el aprendizaje convencional sin uso de la misma y con otros medios audiovisuales, reflejan un incremento significativo. En cuanto a la operatividad técnica, [2] un análisis multidisciplinario de publicaciones en Scopus y Web of Science, siguiendo la metodología PRISMA, establece que RA ayuda a los docentes a participar en experiencias y exploraciones, teniendo un impacto positivo en la motivación y satisfacción de estudiantes, orientándolos hacia un pensamiento crítico. De acuerdo con [3], en una revisión de artículos científicos la aplicación de RA puede ser multidisciplinaria, abarcando un amplio espectro de objetivos y métodos. Sin embargo, también se han observado efectos negativos, siendo los más significativos las diferencias entre los canales de aprendizaje propios de cada estudiante [1], además de complicaciones en el uso, así como elaborar una detallada y correcta guía al implementarla [2], y finalmente, que los elementos aumentados proporcionan una sobrecarga o saturación cognitiva que se transforman en efectos negativos o distractores al usuario [3].

Siendo los dispositivos móviles los medios más populares dentro de las tecnologías emergentes [4], y al considerar su uso en el entorno educativo, y de acuerdo con estudios sobre el impacto del uso de celulares en la estimulación del aprendizaje, para el empleo de RA con propósitos pedagógicos [5], es necesario estimar una valoración y redirigir las situaciones de distracción y dispersión de la atención con el uso de celulares en el aula [6]. Es evidente que se han logrado avances significativos en la diversificación de herramientas de hardware y software con propósito educativo [2], ya que aprovechan el creciente uso de tecnologías emergentes inmersas en las escuelas por parte de los estudiantes de preescolar, primeria y superior básica, en especial de secundaria y preparatoria [7]. Y es en esa dirección hacia donde se enfocó la presente investigación [8]. De ahí se desprende el objetivo que persigue este trabajo, que es caracterizar y conocer la percepción de estudiantes y maestros en el valor del uso de la realidad aumentada en una actividad educativa en escuelas públicas con jóvenes entre 12 y 17 años en una comunidad rural y otra urbana en un estado ubicado en el norte de México, empleando los dispositivos móviles de los estudiantes.

\subsection{Estado del arte de la realidad aumentada}

Se representa con las iniciales $\mathrm{AR}$, por sus conceptos en inglés de augmented reality, y se basa en integrar elementos virtuales como imágenes de dos o tres dimensiones, texto y/o audio a un libro, plano o escenario real, el cual se genera mediante un reconocimiento de imagen (patrón) o de ubicación satelital (GPS). Este reconocimiento se realiza con una aplicación de RA instalada en un celular o tableta [9].

El primer concepto sobre realidad aumentada fue propuesto por un investigador de Boeing cuando estaba trabajando sobre los tableros aéreos y propuso anteojos especiales y tableros virtuales, indicando el investigador como "aumentado" a la realidad del usuario [10].

El concepto más reconocido y adecuado para realidad aumentada es el siguiente: "Una forma de realidad virtual donde el dispositivo montado en la cabeza del participante es transparente, lo que permite una visión clara de la realidad" [11]. 
Para interpretar mejor el concepto de realidad aumentada, en el esquema de la Figura 1 puede observarse el tipo de ambiente, los elementos que los constituyen y el grado de inmersión que se experimenta con realidad virtual, realidad aumentada y un escenario real percibido por el estudiante o el docente.
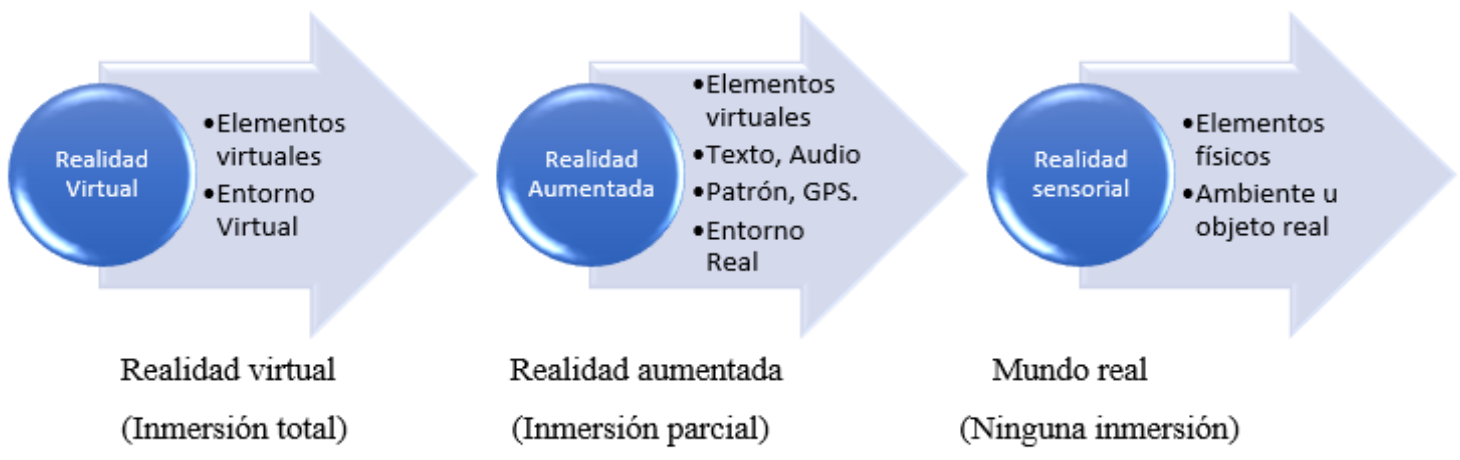

Mundo real

Figura 1. Comparación entre elementos de realidad virtual, realidad aumentada y realidad física Fuente: elaboración propia.

Existen distintos proyectos e investigaciones sobre realidad aumentada en educación, sobre los cuales se han identificados ventajas y desventajas al implementarlos (ver Tabla 1).

Entre las aportaciones más significativas, [1] indica que incrementa la comprensión y mejora el entendimiento, retención en memoria de largo plazo, además de que estimula la colaboración y motivación del estudiante; por su parte, [2] refiere que RA genera un aumento de actitudes positivas hacia la asignatura donde se aplica, mejorando la comunicación a través de la colaboración y el pensamiento crítico en la resolución de problemas.

Comparado con realidad virtual (RV) es menos compleja, más adaptable e interoperable y causa menos malestar de concentración al desplazarse o practicar una simulación [2]. En un análisis de trabajos y publicaciones científicas [3], se plantea RA como una tecnología multidisciplinaria que abarca un amplio espectro de objetivos y métodos. Los beneficios obtenidos con el uso de RA son significativamente mayores que las desventajas que implica su utilización. En cuanto a los efectos negativos que coinciden es que causa distracción, es difícil de usar y puede resultar costoso.

\subsection{Aprendizaje Basado en Problemas (ABP)}

Se tomó la metodología del ABP, porque es "el Aprendizaje Basado en Problemas ABP está fundamentado en el aprendizaje activo y en la autonomía del estudiante" [12], donde el profesor funge como guía y orientador en las etapas de enseñanza-aprendizaje. Los pasos considerados para diseñar la actividad didáctica fueron los siguientes:

(a) Escenario del problema. ¿Cuál es la distribución actual del salón de clases?

(b) Lista sobre lo que ya se conoce. Conocimientos previos o iniciales.

(c) Enunciado inicial del problema. ¿Cuál es el problema principal en la distribución actual del salón?

(d) Lista lo que necesita ser conocido y donde se va a consultar. Información consultada sobre distribución de conferencias, cursos, presentaciones en escuelas y sus horarios en la escuela.

(e) Acciones para seguir. Recomendaciones en tipo de distribución por tipo de asignatura.

(f) Evaluar información recopilada. Conclusiones sobre resultados obtenidos.

(g) Retroalimentación. Opinión de compañeros de clase. 
Tabla 1. Ventajas y desventajas sobre realidad aumentada aplicada en la educación. Fuente: elaboración propia.

\begin{tabular}{|c|c|c|}
\hline \multicolumn{3}{|c|}{ Realidad Aumentada en la educación } \\
\hline Ventajas & Desventajas & Fuente \\
\hline $\begin{array}{l}\text {-Incrementa comprensión del contenido. } \\
\text {-Mejora el entendimiento simbólico. } \\
\text {-Incrementa la retención en memoria de largo } \\
\text { periodo. } \\
\text {-Incrementa la mejora en el rendimiento físico. } \\
\text {-Mayor colaboración interactiva. } \\
\text {-Mejora motivación del estudiante. }\end{array}$ & $\begin{array}{l}\text {-Desviación de la atención } \\
\text { (Tunneling). } \\
\text {-Dificultades en utilización. } \\
\text {-Integración del salón de } \\
\text { clases inefectiva. } \\
\text {-Diferencias en canales de } \\
\text { aprendizaje. }\end{array}$ & $\begin{array}{l}\text { "Augmented } \\
\text { reality } \\
\text { education: in } \\
\text { meta-review and } \\
\text { cross-media } \\
\text { analysis" [1]. }\end{array}$ \\
\hline $\begin{array}{l}\text {-Ayuda a los docentes a participar en experiencias } \\
\text { y exploraciones en el mundo real. } \\
\text {-Facilita percibir eventos o circunstancias. } \\
\text {-Aumenta la motivación y satisfacción de los } \\
\text { estudiantes. } \\
\text {-Ayuda en adquisición de habilidades } \\
\text { investigativas. } \\
\text {-Facilita la creación de entornos de aprendizaje con } \\
\text { elementos reales } \\
\text { y virtuales. } \\
\text {-Ayuda al fomento y desarrollo del pensamiento } \\
\text { crítico y capacidad en resolución de problemas. } \\
\text {-Favorece la comunicación con base en tareas } \\
\text { colaborativas. } \\
\text {-Aumento de actitudes positivas en asignatura. }\end{array}$ & $\begin{array}{l}\text {-Dificultades y problemas } \\
\text { técnicos en el uso. } \\
\text {-Es necesaria una correcta y } \\
\text { detallada guía de la actividad } \\
\text { para que no sea demasiado } \\
\text { complicada para los alumnos. } \\
\text {-Una gran cantidad de } \\
\text { lectura previa es } \\
\text { indispensable para un } \\
\text { correcto uso. }\end{array}$ & $\begin{array}{l}\text { "La trascendencia } \\
\text { de la Realidad } \\
\text { Aumentada en la } \\
\text { motivación } \\
\text { estudiantil. Una } \\
\text { revisión } \\
\text { sistemática y } \quad y \\
\text { meta-análisis" } \\
\text { [2]. }\end{array}$ \\
\hline $\begin{array}{l}\text {-Los campos de aplicación son multidisciplinarios. } \\
\text {-Se abarcan un amplio espectro de objetivos y } \\
\text { métodos. } \\
\text {-Son más los beneficios que experimentan los } \\
\text { estudiantes que las desventajas. } \\
\text {-Existe interacción en el contexto real. } \\
\text {-Se pueden ver elementos de realidad aumentada } \\
\text { con marcadores en tiempo real. }\end{array}$ & $\begin{array}{l}\text {-Sobrecarga o saturación } \\
\text { cognitiva. } \\
\text {-Distracción. }\end{array}$ & $\begin{array}{l}\text { "Augmented } \\
\text { reality for } \\
\text { teaching and } \\
\text { learning - a } \\
\text { literature review } \\
\text { on theoretical and } \\
\text { empirical } \\
\text { foundations"[3]. }\end{array}$ \\
\hline
\end{tabular}

\section{3 Área de estudio}

Este estudio se efectuó en tres comunidades ubicadas en el estado de Baja California en México, limítrofe con Estados Unidos al Noroeste del país. Se seleccionaron dos comunidades rurales localizadas al sur del estado, la Colonia Vicente Guerrero y el Ejido Padre Kino, y una comunidad urbana representada por la capital del estado, que es la ciudad de Mexicali.

En conformidad con [13], en la comunidad de Vicente Guerrero se tiene una población de 11455 habitantes, de los cuales el 40.88 \% es indígena; la oferta educativa para la educación básica está representada por tres escuelas primarias, dos secundarias y dos telesecundarias (un modelo educativo basado en la proyección en televisión de programas educativos recibidos por satélite y ejercicios guiados por un maestro en el aula), además de un colegio privado que ofrece bachillerato, licenciatura y algunas maestrías. Por su parte, en la comunidad rural del Ejido Padre Kino hay 735 habitantes, con un $20.41 \%$ de población indígena; la oferta educativa se compone de dos primarias, dos telesecundarias, una preparatoria pública y una universidad técnica también pública.

Por su parte, en la comunidad urbana de Mexicali viven aproximadamente un millón de personas, de los cuales solamente 7200 son indígenas. Por asistencia escolar, los aprendices de 3 a 14 años acuden en un $85.7 \%$ a alguna escuela de educación básica, mientras que entre los jóvenes de 15 a 17 años, el $77.99 \%$ asisten a una escuela de bachillerato y, de entre los jóvenes de 18 años, el $29 \%$ se presenta a alguna universidad [14]. En el estado de Baja 
California, cerca del 80 \% de la población (alrededor de tres millones de habitantes) se ubica en una franja que va de la frontera con los Estados Unidos hasta los 125 kilómetros al sur, en donde se ubica la ciudad de Ensenada, siendo este un estado con aproximadamente 700 kilómetros de extensión de norte a sur.

Las comunidades de Vicente Guerrero y Ejido Padre Kino en San Quintín, al estar al sur de la franja de la mayoría poblacional (166 km y $172 \mathrm{~km}$ al sur de la ciudad de Ensenada, respectivamente), tienen serias restricciones en la cantidad y calidad de infraestructura y servicios de comunicación tanto física como digital. El servicio de acceso a internet es provisto por cable por la principal compañía telefónica y de manera inalámbrica por las compañías de telefonía celular y algunas compañías satelitales. Sin embargo, la economía local no permite que todas las familias tengan conectividad de banda ancha y que no todos sus miembros tengan acceso a su propio dispositivo de cómputo móvil o fijo. Evidentemente, al considerar su empleo en la educación estas situaciones limitarán de alguna manera su efectividad. En la ciudad de Mexicali no existen estas limitaciones por ser una ciudad donde se tiene una buena cantidad de infraestructura de comunicaciones y con una oferta amplia en cantidad y calidad de proveedoras de servicios.

En México, cada dos años se aplica un examen estandarizado llamado Planea, el cual está dirigido a jóvenes de sexto año de primaria (12 años) y tercer año de secundaria (15 años) [15].

En esta prueba se evalúan aspectos relacionados con los aprendizajes en el uso y comprensión del lenguaje (en este caso asociado al idioma español), de comunicación, de matemáticas, así como habilidades socioafectivas. Las mediciones obtenidas en Matemáticas reflejan una media nacional de 497 puntos. En Baja California la media fue de 494 puntos en las secundarias públicas y de 419 puntos en la zona comunitaria o rural [16], ubicándose la media estatal por debajo de la media nacional. Comparando el puntaje obtenido en Baja California por niveles de marginación (asociada al sur del Estado), la media fue de 488 puntos.

En términos de marginación clasificada como "Alta" y "Muy alta", la media fue de 473 puntos [16].

\section{METODOLOGÍA}

Se seleccionó la metodología de investigación-acción como la base en que se fundamenta este estudio, porque es donde el investigador forma parte de la intervención [17]. El enfoque es del tipo mixto con alcance exploratorio, puesto que por un lado se retoman elementos del corte cualitativo y/o cuantitativos derivados de la investigación. Los resultados obtenidos forman la base para futuros proyectos de aplicación con RA en el sector educativo.

Siguiendo el diseño explicativo secuencial (DEXPLIS) [18], en la primera etapa se recaba y evalúa la información cuantitativa(instrumento de análisis diagnóstico), posteriormente se recoge y analiza la información cualitativa (percepción de alumnos y maestros), luego se analizan y discuten los descubrimientos cuantitativos y cualitativos en el apartado de Discusiones y Conclusiones incluidas en este artículo.

El diseño de la investigación, planeación, ejecución y análisis se organizó en cinco etapas:

a) Análisis del estado del arte. Se elaboró una evaluación descriptiva de estudios previos de la aplicación de la RA en el sector educativo y sus efectos en los estudiantes [4], [5], [19].

b) Selección de factores del estudio. Se valoraron aspectos culturales, económicos, políticos, sociales, técnicos y tecnológicos de la región sur del estado de Baja California, enfocado en la colonia Vicente Guerrero y en el centro poblacional Ejido Padre Kino del municipio de San Quintín, esto con la finalidad de caracterizar la disponibilidad de servicios de comunicación y 
la disponibilidad de infraestructura de comunicación que requeriría el uso de software para la realidad aumentada en el sector educativo de esta región del país.

c) Diseño de instrumentos para recopilación de información. Evaluación de factibilidad de la implementación y de la percepción de la actividad educativa empleando RA. Estas herramientas se desarrollaron en tres prototipos: (1) Análisis diagnóstico previo a la actividad por estudiantes. (2) Percepción de alumnos de nivel secundaria y preparatoria del uso de la $R A$. (3) Percepción de maestros del uso de la RA.

d) Diseño de actividad didáctica y aplicación móvil RA. Se desarrolló una actividad educativa empleando los dispositivos móviles de los estudiantes.

e) Evaluación de la aplicación de RA. Se evaluó la utilización de esta tecnología en los diversos contextos asociados a las áreas de estudio.

Para el diseño de la actividad educativa empleando RA, se consideró el modelo de realidad aumentada, construido a partir de la revisión del estado del arte, el cual contiene diversas categorías como área, rol de apoyo, recursos móviles, tipos de escenarios, recursos interactivos educativos, disciplinas y parámetros de análisis. Estas categorías surgen a partir de lo expuesto por [20] para recursos móviles. También se consideraron los estudios sobre recursos educativos e interactivos [21], así como un análisis de parámetros de medición de realidad aumentada en educación básica [1] y otras categorías incorporadas por los autores que se consideraron importantes. A la integración de estos elementos se le llamó Modelo de Realidad Aumentada en la Educación (MRAE).

La primera categoría del MRAE es Área, en la que se define el lugar para desarrollar las actividades, ya sea en interiores o exteriores del salón de clases. La segunda categoría es Rol de Apoyo, la cual considera la forma en la que el maestro o facilitador interactúa con el grupo, pudiendo ser de manera presencial, en donde el maestro monitorea por observación a cada alumno, o a distancia, con estrategias de control de detección de alumnos con dispositivos de tecnología de la información y comunicación. En la tercera categoría, Recursos, se consideraron los recursos móviles para proponer distintas alternativas de trabajo con la realidad aumentada; entre éstas se encuentran aplicaciones móviles de RA, plataformas o programas con RA, dispositivos móviles alternativos y dispositivos portables adaptativos (HMDs). La cuarta categoría, Tipos de Escenarios, considera las diversas situaciones de aprendizaje que intervienen, ya sea con recursos como videos, imágenes, audio, por geolocalización, con realidad virtual y, por supuesto, con realidad aumentada. La quinta categoría es la de Recursos Educativos Interactivos, la cual incorpora, a los recursos educativos e interactivos que auxilien a crear, estrategias educativas, colaborativas, interactivas y lúdicas basadas en competencias. La categoría seis, Disciplinas, considera a las distintas profesiones terminales donde se ha implementado la RA. Por último, la categoría siete, Parámetros de Análisis, incorpora a los parámetros de interés para determinar diferentes aspectos a evaluar con el objetivo de monitorear el aprendizaje o efecto de la implementación en distintos canales de aprendizaje.

\subsection{Criterios de selección de la muestra o sujetos de estudio}

Los sujetos de la investigación fueron seleccionados bajo los siguientes criterios:

A. Selección de estudiantes:

A.1. Estudiantes activos de secundaria o preparatoria.

A.2. Tener un rango de edad de 12 a 17 años.

A.3. Género: indistinto.

A.4. Raíces étnicas: indistintas. 
A.5. Idioma: español, ya sea como lengua materna o segunda lengua (dominio intermedio del español).

A.6. Necesidades educativas especiales: indistintas.

B. Selección de docentes:

B.1. Docentes activos frente a grupo.

B.2. Experiencia docente: dos años de antigüedad en adelante.

B.3. Género: indistinto

B.4. Raíces étnicas: indistintas

B.5. Idioma: español, ya sea como lengua materna o segunda lengua (dominio intermedio del español).

B.6. Formación: Licenciatura en Ciencias Exactas y Experimentales.

C. Escuelas:

C.1. Localidad: la escuela debe estar situada en cualquiera de los cinco municipios de Baja California.

C.2. Económica: estar ubicada dentro de una comunidad rural de media o alta marginación.

C.3. Que exista una correspondencia directa entre el currículo de la escuela y la temática computacional.

C.4. Que sea posible implementar una situación didáctica con alta sensibilidad a la instrucción en una de las asignaturas.

C.5. Tipo de sostenimiento: escuela pública.

\subsection{Descripción de instrumentos de recopilación de datos utilizados}

En este estudio se utilizaron tres instrumentos, los cuales corresponden a diversos momentos de la investigación; el primer instrumento es el de una evaluación diagnóstica MobiApp2RA, el cual consiste en 29 ítems distribuidos en seis módulos: Identificación, Seguridad y riesgo, Información sobre el dispositivo, Caracterización de señal, Uso de dispositivo e Instalación de la App. Se utilizaron ítems en respuesta cerrada y escala de Likert. La aplicación fue en línea, tomando en cuenta las indicaciones para las evaluaciones de ejecución típica a gran escala, así como la identificación de sujetos clave, quienes fueron los estudiantes y docentes de escuelas públicas de Baja California. El segundo instrumento contiene 28 ítems distribuidos en cinco módulos: Identificación, Educación y prevención, Software educativo, Experiencia en el uso de MobApp-RA-2D y Reconocimiento de los marcadores y arquitectura educativa. Este instrumento consta de respuestas cerradas, escala de Likert y dos ítems de respuesta abierta para recopilación de experiencias de los alumnos en el uso de la App. El tercer instrumento contiene 36 ítems distribuidos en ocho módulos: Identificación, Contexto áulico, Actividad App, Uso de TIC, Aceptación de la RA, Actitud hacia la RA, Aprendizaje utilizando RA y Amigabilidad de la RA. En este último instrumento se incluyeron preguntas abiertas sobre el desarrollo de la actividad desde la perspectiva del maestro, así como algunas preguntas de respuesta cerrada, aunque la mayoría fueron establecidas en escala de Likert.

\subsection{Validación de los instrumentos utilizados}

Estos instrumentos han sido validados considerando los constructos correspondientes a la realidad aumentada y relacionados con Aprendizaje Basado en Problemas (PBL por sus siglas 
en inglés), además de considerar la validez de contenido fortalecida con los juicios emitidos por dos especialistas en este rubro, quienes por una parte apoyaron la revisión lógica, mientras que por la otra sugirieron algunos ejercicios de selección y comprobación sobre el funcionamiento de los ítems y de la consistencia del funcionamiento en las estrategias de recolección y análisis de datos. Los especialistas establecieron los procedimientos de revisión lógica, así como los análisis de estructura interna y de relación de los ítems con las variables preestablecidas por los expertos.

\subsection{Diseño de la aplicación MobiAppRA2D}

Para desarrollar la aplicación se consideraron varias etapas, entre ellas el tema educativo y objetivos de la aplicación. El tema que se trabajó fue la distribución de mobiliario por actividad educativa con enfoque en la prevención. Los objetivos educativos que se persiguieron fue el de relacionar y organizar figuras en un área definida, utilizando principios básicos de geometría en localización y distribución de equipos. Entre los objetivos técnicos se establecieron:

1. Definir aplicación para recrear RA.

2. Que la aplicación fuera fácil de descargar y usar en equipos.

3. Disponibilidad de soporte Wifi.

4. Elaborar elementos descriptivos.

\subsubsection{Estudio piloto para determinar los requerimientos de la aplicación}

Se realizó una actividad educativa en tres escuelas de Mexicali (dos de la ciudad y una del Valle de Mexicali); cada grupo participante tenía un promedio de 35 estudiantes por grupo, se trabajó con la aplicación de Aurasma para el reconocimiento de patrones de realidad aumentada, los cuales mostraban un video con una situación de riesgo para que los estudiantes las identificaran en un mapa de riesgo para la escuela; el instrumento diagnóstico de los equipos disponibles arrojó la siguiente información: la mayoría usa celular (74), de los cuales 50 son de plataforma Android y 24 son de Apple / iOS, la definición de la cámara está en el rango de 3 a 12 megapíxeles, y el tiempo de reconocimiento por marcador tuvo una frecuencia de 8 segundos o más.

\subsubsection{Arquitectura del Proyecto MobiAppRA2D}

De los datos obtenidos en el estudio piloto se determinó la aplicación Android con un tamaño de 50 megas de memoria, la cual se reprodujo a través de la plataforma de desarrollo Unity en combinación con la herramienta de desarrollo de realidad aumentada Vuforia. La aplicación Pixlr facilitó que los marcadores alcanzaran un reconocimiento óptimo de 4 a 5 estrellas en Vuforia para que el tiempo de reconocimiento fuera el mínimo posible. El proceso de funcionamiento de la aplicación se puede ver en la Figura 2. 


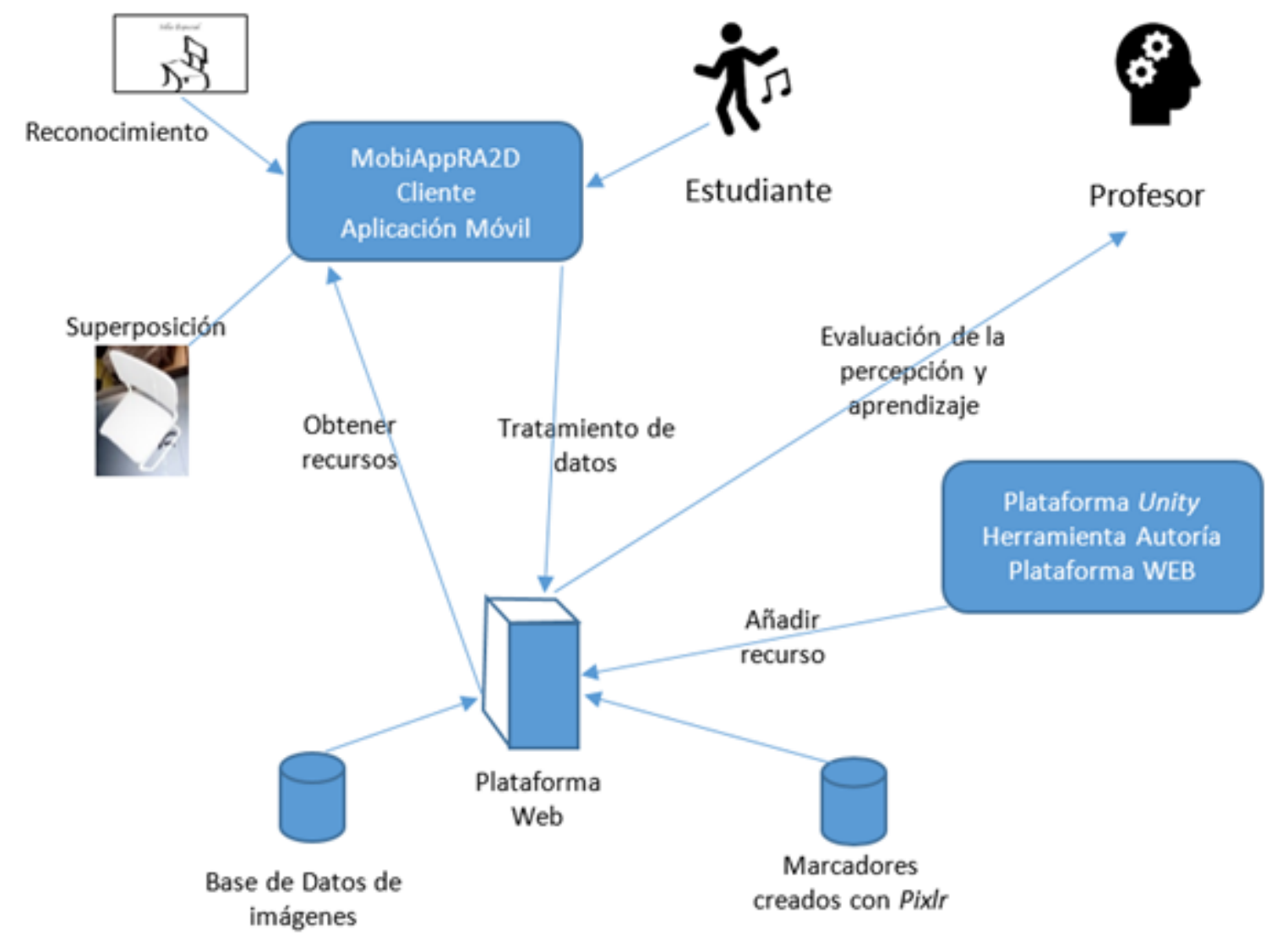

Figura 2. Elementos que conforman la aplicación MobiAppRA2D. Fuente: elaboración propia.

\section{RESULTADOS}

Para la realización de la intervención didáctica se diseñó una actividad que considerara la distribución del mobiliario de un salón de clases. Una vez definido el tema, se aplicaron las siete categorías descritas, siendo la primera la que se determinó como Área de trabajo del salón de clases, el Rol de apoyo para el maestro, incluyendo las instrucciones para realizar la actividad educativa e instrucciones para descargar la aplicación al celular. En los Recursos móviles se incorporan alternativas para diseñar software de RA como Unity / Vuforia (3.1.6); se establecieron varios Tipos de escenarios con RA en dos y tres dimensiones; para los Recursos educativos interactivos de la actividad didáctica se optó por estrategias de aprendizaje colaborativo y aprendizaje basado en problemas; finalmente se definieron los Parámetros de análisis para evaluar la experiencia de parte de estudiantes y profesores.

Siguiendo la secuencia del aprendizaje basado en problemas, la actividad didáctica se distribuyó en sesiones de 50 minutos (que es la duración típica de una sesión de clase) durante cinco días.

\subsection{Acerca de las escuelas participantes}

Las características de las escuelas y grupos participantes se observan en la Tabla 2 (el Grupo 1 y el Grupo 2 son de la Escuela A), considerando el sector económico donde laboran los padres de los estudiantes y cantidad de alumnos por grupo. Con base en estos datos del estudio, se evaluaron fundamentos de matemáticas, identificación y aplicación de figuras 
geométricas en el diseño estructural del mobiliario, seleccionando las figuras más adecuadas para la organización del mobiliario, así como flujos de circulación y determinación de las restricciones físicas trabajando en equipo. Asimismo, se trabajó con objetivos técnicos para definir cómo utilizar la aplicación para que esta fuera fácil de descargar y utilizar en cualquier dispositivo móvil y proporcionar el soporte de internet inalámbrico necesario en estos dispositivos, además de elaborar y/o asociar imágenes descriptivas relacionadas con el mobiliario regular de un salón de clases. Por último, se proporcionaron alternativas para calcular el área o perímetro si así lo considerasen necesario.

Tabla 2. Descripción de las escuelas participantes (La Escuela A tiene el Grupo 1 y el Grupo 2) Fuente: elaboración propia.

\begin{tabular}{|c|c|c|c|}
\hline Escuela & Grupo signatura & Sector económico & Alumnos \\
\hline $\mathrm{A}$ & $\begin{array}{l}\text { Grupo } 1 \text { - Primer Grado, } \\
\text { Clase de Matemáticas }\end{array}$ & $\begin{array}{c}\text { Campo (5), Pesca (0), Público (6), } \\
\text { Privado (12) y Autoempleo (11) }\end{array}$ & 34 \\
\hline A & $\begin{array}{l}\text { Grupo } 2 \text {-Primer Grado, } \\
\text { Clase de Matemáticas }\end{array}$ & $\begin{array}{l}\text { Campo (4), Pesca (1), Público (8), } \\
\text { Privado (1) y Autoempleo (7) }\end{array}$ & 32 \\
\hline B & $\begin{array}{l}\text { Grupo } 3 \text { - Tercer Grado, } \\
\text { Clase de Módulo }\end{array}$ & $\begin{array}{l}\text { Campo (7), Pesca (2), Público (8), } \\
\text { Privado (4) y Autoempleo (7) }\end{array}$ & 40 \\
\hline $\mathrm{C}$ & $\begin{array}{c}\text { Grupo } 4 \text { - Primer Grado, } \\
\text { Clase de Matemáticas }\end{array}$ & $\begin{array}{c}\text { Público (14), Privado (6) y } \\
\text { Autoempleo (2) }\end{array}$ & 36 \\
\hline
\end{tabular}

\subsection{Levantamiento previo sobre dispositivos móviles de los estudiantes}

En la Tabla 3 se puede observar el estudio diagnóstico de las escuelas a realizar la actividad. En las escuelas de Vicente Guerrero y Ejido Padre Kino de San Quintín se les requirió especificar información del dispositivo, características de las señales de red disponible; el tipo de dispositivo más usual fue que carecen de celular la mayoría de los estudiantes de San Quintín: Grupo 1, el 56 \% (19/34); Grupo 2, el 66 \% (21/32) en Escuela A; y Escuela B en Grupo 3, el 75 \% (30/40). Contra Mexicali, en Escuela C y Grupo 4, con sólo $5.6 \%(2 / 36)$ que no tenían celular; sobra mencionar que en Vicente Guerrero y Ejido Padre Kino de San Quintín presentaban un escenario muy adverso en comparación a Mexicali.

Una vez cotejada la disponibilidad de equipos celulares, se procedió a analizar los tipos de sistemas operativos de los aparatos celulares, quedando con plataforma Android de la siguiente manera: Grupo 1, el 76.5 \% (13/17); Grupo 2, el $100 \%$ (13/13); Grupo 3, el $86.7 \%$ (13/15); y Grupo 4, el $75 \%$ (24/32).

El sistema operativo Android fue el más aceptado: del 75 \% (Grupo 4 - Mexicali) al $100 \%$ (Grupo 2 - Vicente Guerrero) y las series de Android 5.0 y 6.0 tuvieron una frecuencia del $61 \%$ al $92 \%$, aunque en Mexicali el $41.7 \%$ (10/24) indicaron el 1.1 Petite four, por lo cual se infiere que fue más típico el celular Android de la serie 5.0 o 6.0 el más común.

También se muestra una opinión sobre las disponibilidades de red en el aula de medios: tiene preferencias del $46 \%$ (6 de 13) al $59 \%$ (10/17) y $64.7 \%(22 / 34)$ en Mexicali; los estudiantes que no saben de cuánto es la capacidad de red son del $46 \%(7 / 15)$ hasta el $77 \%$ (10/13) o el $47 \%$ en Mexicali; y, por último, en biblioteca se tiene la mayor intensidad de la señal, pues hay una preferencia del $38 \%(5 / 13)$ al $100 \%(15 / 15)$ y $50 \%(17 / 34)$ en Mexicali.

En general, se identificó una poca disponibilidad de dispositivos móviles en las escuelas rurales en comparación con la escuela urbana. Razón por la cual se identificó que la 
organización de los estudiantes en equipos fue positiva y permitió que todo el grupo pudiera utilizar la aplicación de RA. Los habitantes atribuyen a la falta de antenas o la cercanía con las montañas una intermitencia y debilidad de la señal para la conexión a internet. Esta intermitencia ocasionó problemas e interrupciones durante el proceso de descarga de la aplicación.

Tabla 3. Levantamiento previo sobre dispositivos móviles de los estudiantes. Fuente: elaboración propia.

\begin{tabular}{|c|c|c|c|c|c|c|c|c|c|c|c|c|}
\hline \multicolumn{13}{|c|}{ II. Información sobre dispositivo } \\
\hline & \multicolumn{4}{|c|}{ II.1. Tipo } & \multicolumn{4}{|c|}{ II.2. Sistema Operativo } & \multicolumn{4}{|c|}{ II.3 Versión Android } \\
\hline & $\begin{array}{l}\text { Smart } \\
\text { phone }\end{array}$ & Tableta & Celular & No tiene & $\begin{array}{l}\text { Micro- } \\
\text { soft }\end{array}$ & IOS & Android & $\begin{array}{l}\text { Android } \\
<5.0\end{array}$ & $\begin{array}{c}5.0- \\
5.1 .1 \\
\text { Lollipop }\end{array}$ & $\begin{array}{c}6.0 \\
\text { Marshm } \\
\text { allow } \\
\end{array}$ & $\begin{array}{c}7.0- \\
7.1 .2 \\
\text { Nougat }\end{array}$ & $\begin{array}{c}8.0-8.1 \\
\text { Oreo }\end{array}$ \\
\hline $\begin{array}{l}\text { Grupo } 1 \text { - } \\
\text { rural (Vicente } \\
\text { Gro.17/34) }\end{array}$ & 6 & 7 & 15 & 19 & 0 & 4 & 13 & 0 & 6 & 6 & 1 & 0 \\
\hline $\begin{array}{l}\text { Grupo } 2- \\
\text { rural (Vicente } \\
\text { Gro.13/32) }\end{array}$ & 0 & 2 & 11 & 21 & 0 & 0 & 13 & 0 & 4 & 4 & 2 & 0 \\
\hline $\begin{array}{l}\text { Grupo } 3- \\
\text { rural (Ejido } \\
\text { Padre Kino } \\
\text { 15/40) }\end{array}$ & 1 & 8 & 9 & 30 & 0 & 2 & 13 & 0 & 3 & 6 & 5 & 0 \\
\hline $\begin{array}{l}\text { Grupo } 4- \\
\text { urbana } \\
\text { (Mexicali } \\
34 / 36 \text { ) }\end{array}$ & 15 & 18 & 32 & 2 & 0 & 8 & 24 & 10 & 0 & 1 & 0 & 0 \\
\hline \multicolumn{13}{|c|}{ III. Caracterización escolar en señal de red } \\
\hline & \multicolumn{4}{|c|}{ III.1. Alternativas } & \multicolumn{4}{|c|}{ III.2. Capacidad } & \multicolumn{4}{|c|}{ III.3. Intensidad } \\
\hline & $\begin{array}{l}\text { Escolar } \\
\text { abierta }\end{array}$ & $\begin{array}{c}\text { Biblio- } \\
\text { teca }\end{array}$ & $\begin{array}{c}\text { Aula de } \\
\text { medios }\end{array}$ & $\begin{array}{c}\text { Datos } \\
\text { en plan }\end{array}$ & $\begin{array}{c}\text { No sabe } \\
\text { (señal } \\
\text { siempre) } \\
\end{array}$ & $1 \mathrm{~GB}$ & $2 \mathrm{~GB}$ & $5 \mathrm{~GB}$ & $\begin{array}{c}\text { Biblio- } \\
\text { teca }\end{array}$ & $\begin{array}{c}\text { Aula de } \\
\text { medios }\end{array}$ & Salones & $\begin{array}{l}\text { Dire- } \\
\text { cción }\end{array}$ \\
\hline $\begin{array}{l}\text { Grupo } 1- \\
\text { rural (Vicente } \\
\text { Gro.17/34) }\end{array}$ & 6 & 5 & 10 & 6 & 11 & 1 & 3 & 2 & 12 & 11 & 9 & 8 \\
\hline $\begin{array}{l}\text { Grupo } 2- \\
\text { rural (Vicente } \\
\text { Gro.13/32) }\end{array}$ & 6 & 1 & 6 & 1 & 10 & 0 & 0 & 3 & 5 & 9 & 6 & 9 \\
\hline $\begin{array}{l}\text { Grupo 3- } \\
\text { rural (Ejido } \\
\text { Padre Kino } \\
\text { 15/40) }\end{array}$ & 2 & 10 & 8 & 3 & 7 & 5 & 1 & 2 & 15 & 9 & 3 & 14 \\
\hline $\begin{array}{l}\text { Grupo } 4- \\
\text { urbana } \\
\text { (Mexicali } \\
34 / 36 \text { ) }\end{array}$ & 5 & 9 & 22 & 4 & 16 & 3 & 1 & 0 & 17 & 16 & 14 & 22 \\
\hline
\end{tabular}

\subsection{Diseño de actividad educativa y aplicación de realidad aumentada MobiAppRA2D en Android}

En el día 1, Introducción, se describió la lección sobre distribución del mobiliario de acuerdo con el tipo de actividad educativa y la agenda para desarrollar la lección con RA. Se les instruyó acerca del Aprendizaje Basado en Problemas (ABP) y se les entregó un cuestionario de levantamiento diagnóstico para ser llenado por ellos y que consistía en características de los dispositivos móviles que tenían los estudiantes. 
En el día 2, Organización de la actividad, se presentó la metodología del aprendizaje basado en problemas y el enunciado del problema ¿Cómo puedo mejorar el área en que está distribuido el mobiliario de clase? y se plantearon los objetivos por alcanzar. Debido a que en las poblaciones rurales la mayoría de los estudiantes no poseían dispositivos móviles, se organizaron en grupos de cinco a seis estudiantes que compartían uno o dos de estos dispositivos. Como guía de la actividad se les mostraron diversos tipos de acomodo de mobiliario y se discutieron las ventajas y desventajas de cada uno en diferentes situaciones educativas, siendo estos tipos el acomodo para conferencia, seminario, círculo, grupal frente a frente y grupal cruzado, como se muestra en la Figura 3.

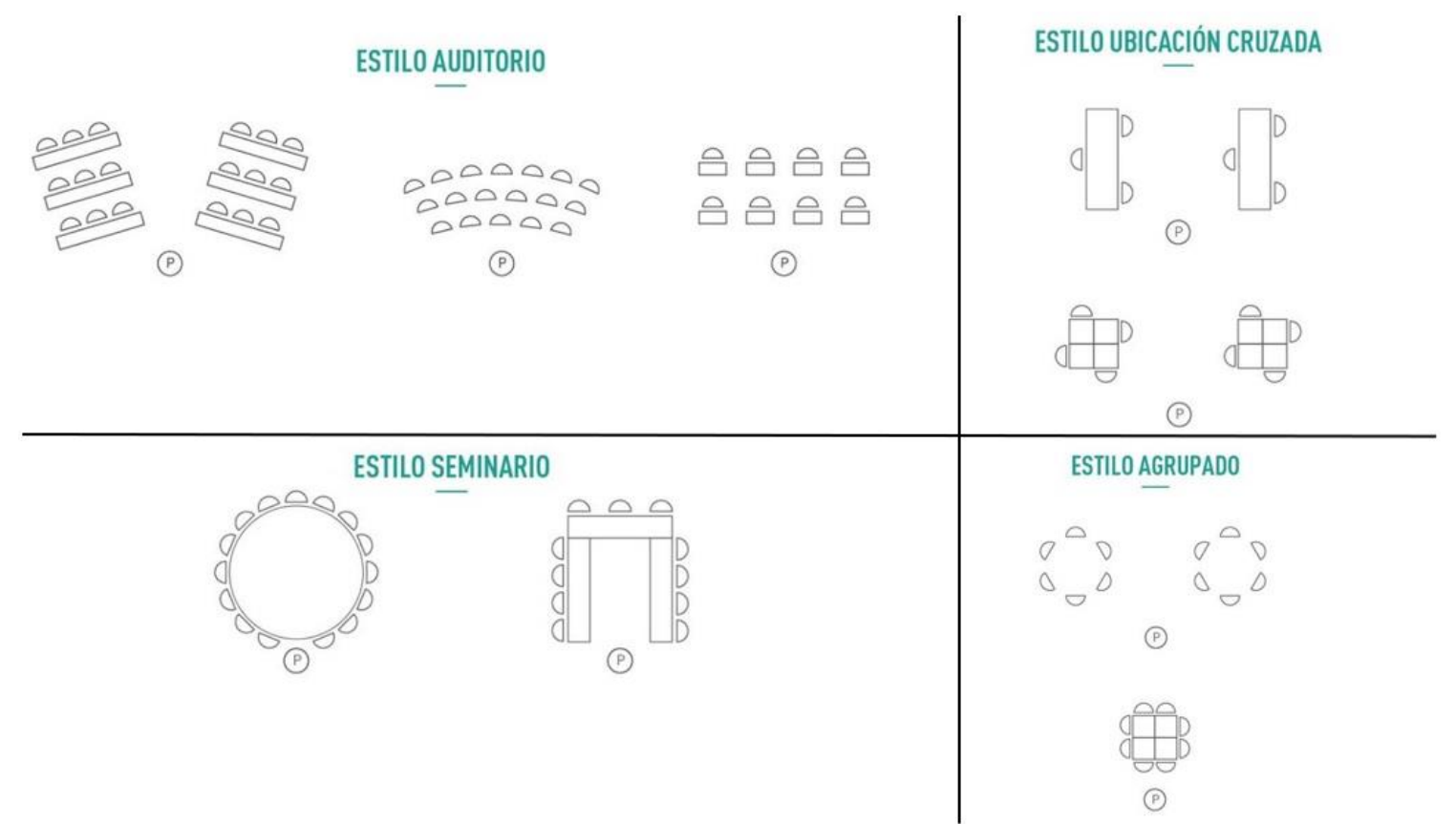

Figura 3. Tipos de acomodo de mobiliario en el salón de clases dependiendo de la actividad a desarrollar Fuente: [22].

Se emplearon dispositivos móviles telefónicos o tabletas con alguna versión del sistema operativo Android mayor a la 5.0 o tableta modelo Android 5.0 o mayor, con espacio disponible para la aplicación (60 Mb), así como marcadores impresos en papel en donde existía uno por cada tipo de mobiliario en el salón de clases (silla ordinaria, silla por necesidades o atenciones especiales, mesa del profesor, librero, proyector y equipo contra incendios) pudiendo emplear más de un marcador de cada tipo. Se les distribuyó una dirección web para la descarga de aplicación por internet. En el caso que se presentaran limitantes con la conexión a internet, era posible instalar la aplicación por vía un cable conectado a la computadora del maestro, o empleando Bluetooth como medio de transferencia entre la computadora y el dispositivo móvil sin tener que acceder a internet.

Los marcadores son reconocidos por la aplicación mediante el uso de la cámara exterior del celular al enfocarla sobre ellos con una inclinación de entre 45 grados a 135 grados. Al reconocer la aplicación, el marcador es sustituido en el video en la pantalla del dispositivo móvil por una imagen tridimensional que lo representa tal y como se muestra en la Figura 4. 

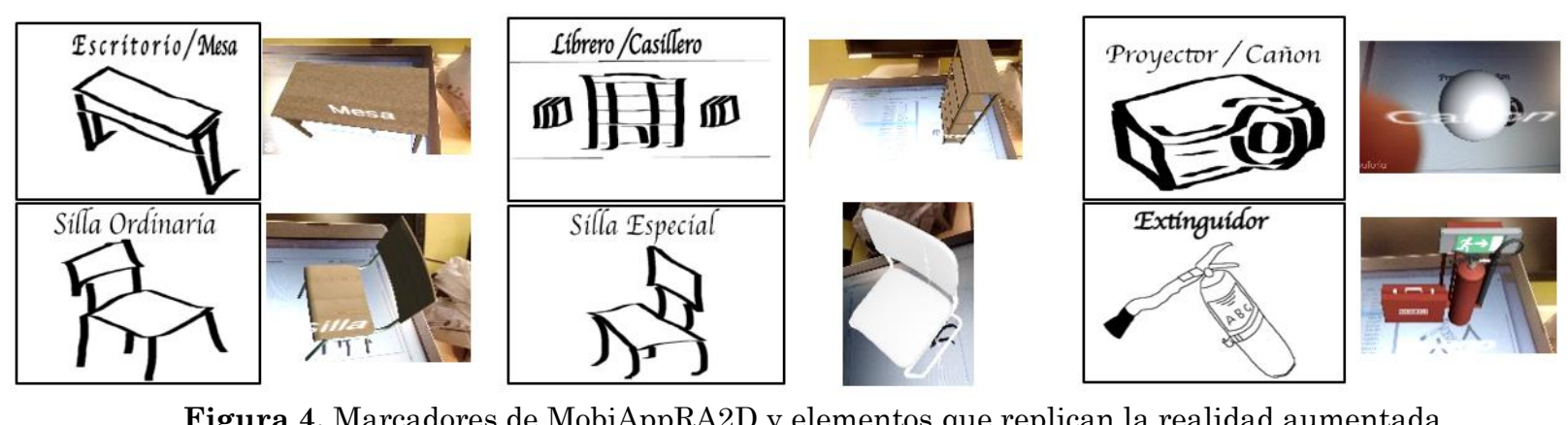

Figura 4. Marcadores de MobiAppRA2D y elementos que replican la realidad aumentada. Fuente: elaboración propia.

En la pantalla del dispositivo móvil, el modelo tridimensional se funde con la imagen del rollo de papel siendo esta la manera de cómo se aplicó la realidad aumentada en la actividad. El uso de esta aplicación de RA con los marcadores colocados en el rollo de papel permitió representar a distintos escenarios reales un escenario a escala de la distribución real del mobiliario que puede ser manipulado y visualizado de forma flexible y práctica. Por otra parte, cabe mencionar que la manera en la que se empleó el dispositivo móvil en este trabajo y que fue provisto por los estudiantes habilitó el uso del software educativo empleando RA en comunidades rurales alejadas de núcleos urbano y que presentan un grado de marginación alto.

En el día 3, Manos a la obra, los estudiantes identificaron lo que conocen y no conocen acerca de la distribución del mobiliario que tenían en ese momento en clase, las posibles contingencias en caso de situaciones de emergencia, los requerimientos para compañeros con necesidades especiales y el equipo de seguridad presente o ausente en el salón de clase.

Empleando un rollo de papel para dibujar, plumones, marcadores, tijeras y pegamento, los estudiantes recortaron los marcadores impresos y los fueron colocando en el rollo de papel representando un acomodo del mobiliario (ver Figura 5) conforme a sus propias propuestas de acuerdo con el escenario seleccionado por ellos, considerando la ubicación del mobiliario y el equipo propuesto a posibles situaciones de ingreso, la actividad educativa y el desalojo en condiciones normales o de alguna situación de riesgo. Podían emplear a los marcadores y plumones para dibujar cualquier elemento complementario que no tuviera asociado un marcador como puertas de emergencia, flujos de ingreso y salida. Los estudiantes que no pudieron completar la actividad en el tiempo convencional se llevaron la cartulina a sus casas para entregarlas al siguiente día.

En el día 4, Documentación y elaboración de reporte, los estudiantes realizaron una presentación ante el profesor de su propuesta mostrando el rollo de papel con los marcadores y dibujos accesorios. Los estudiantes expusieron el razonamiento del porqué habían seleccionado el tipo de distribución apoyándose en la aplicación para RA, la cual mostraba en pantalla la vista de la cámara fotográfica, pero al ir reconociendo los diferentes marcadores, estos eran sustituidos en la pantalla por la representación tridimensional del mobiliario o equipo al que estaba asociado. De esta manera, al ir recorriendo el dispositivo móvil los diferentes marcadores, el efecto fue como navegar a través del salón representado en el rollo de papel, visualizando los modelos tridimensionales de los muebles y el equipo. 


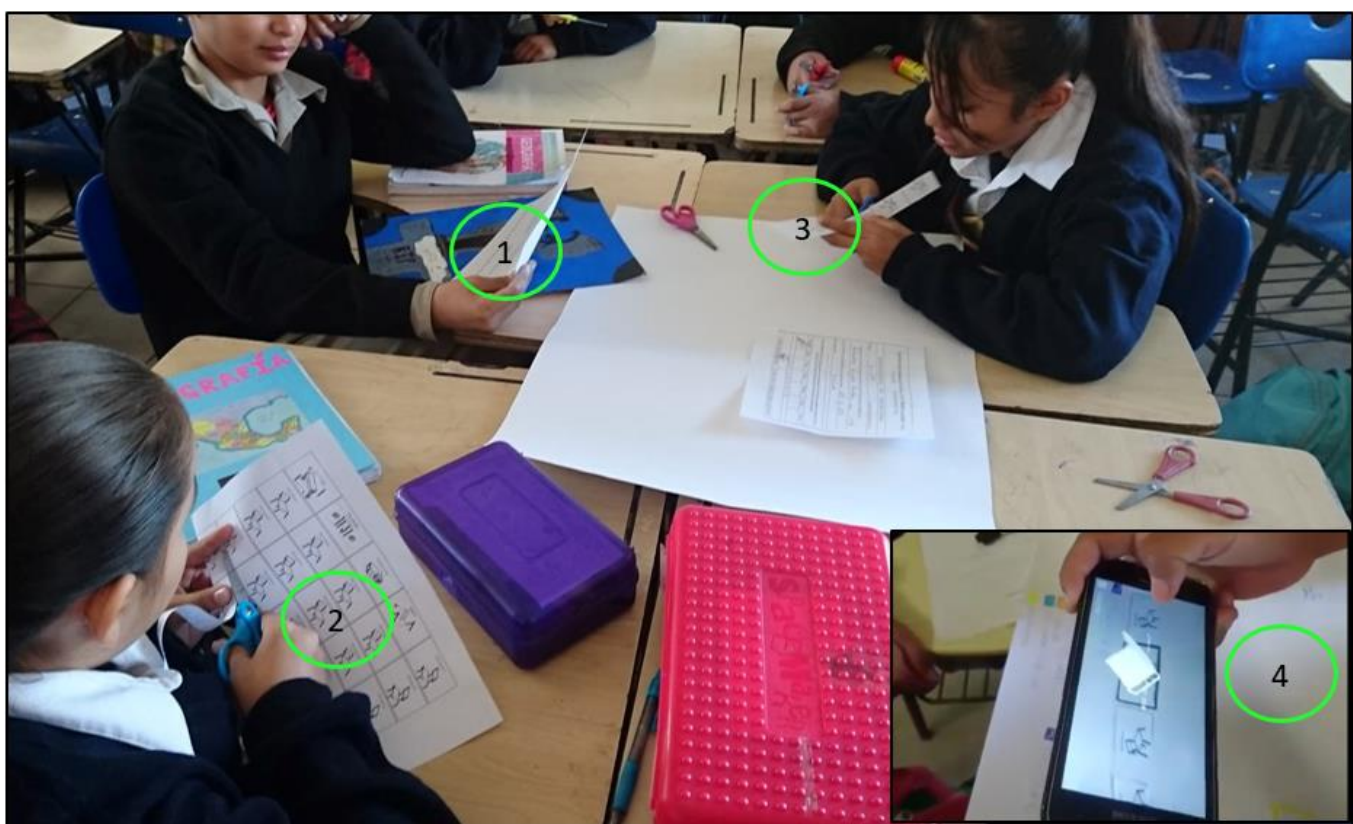

1.Revisar distribuciones 2.Recortar marcadores 3.Pegar marcadores 4.Reconocer marcador

Figura 5. Actividad "Manos a la obra" para organizar el mobiliario. Fuente: elaboración propia.

Por último, en el día 5, Reporte final (ver Figura 6), el grupo discutió en reunión plenaria los resultados de la actividad e intercambiaron ideas y puntos de vista acerca de la actividad, la importancia de la prevención, propuestas de alternativas de solución ante situaciones imprevistas y su experiencia durante el proceso de la actividad educativa. Para concluir se aplicó un instrumento de percepción de la actividad a estudiantes y maestros.
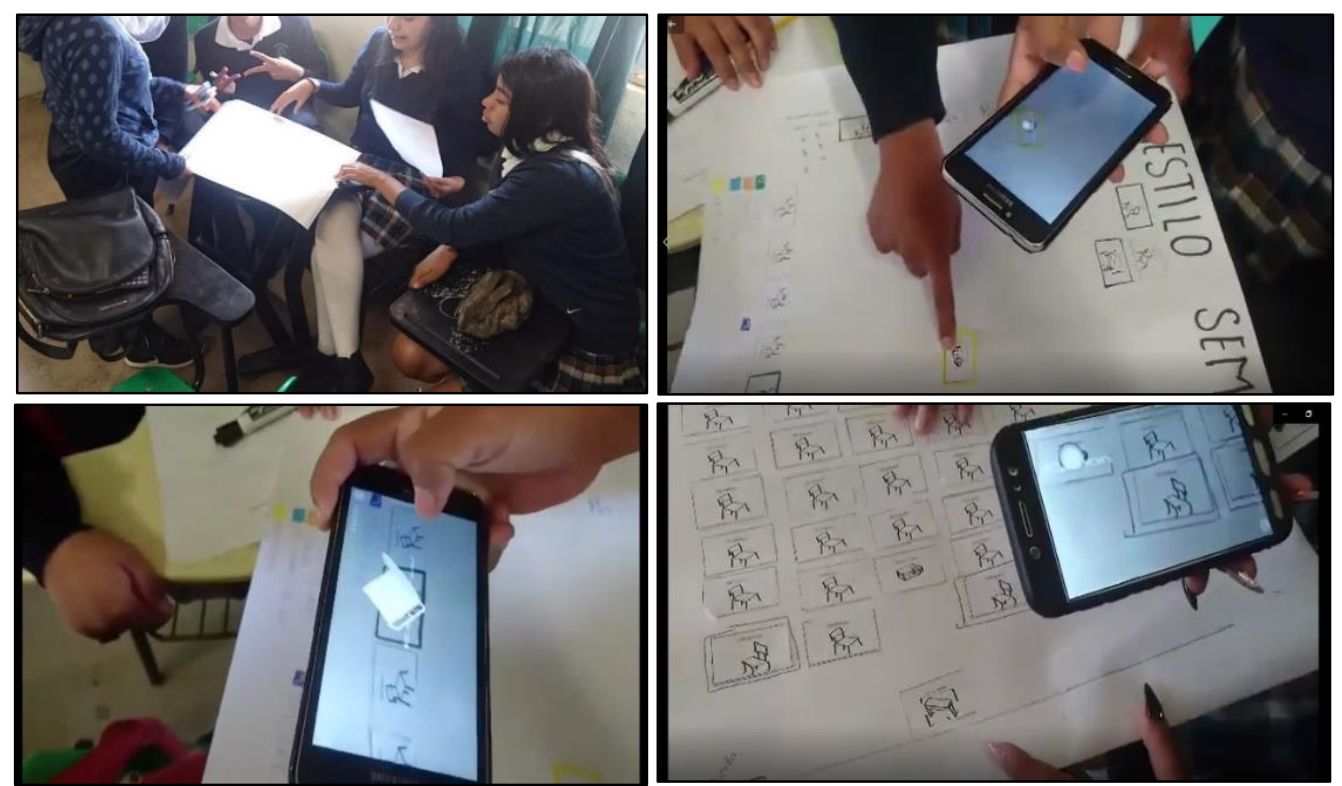

Figura 6. Discusión sobre los escenarios de cada distribución. Fuente: elaboración propia. 


\subsection{Opinión sobre contexto escolar y entorno áulico inmediato de estudiantes}

En la Tabla 4 se ilustran los factores experimentados por los estudiantes en las actividades, visualizando dichos aspectos de interés y generando soluciones rápidas en el estudio elaborado, las cuales reflejan en el punto II.1 Prevención, como Útil y Muy útil 93.94 \% (31/33), $95 \%$ (19/20), $89.28 \%$ (25/28) y $73.53 \%$ (25/34) del Grupo 1 al Grupo 4 en ese mismo orden. En cuanto a estudiantes que interactúan con estudiantes de necesidades educativas especiales (NEE), respondieron qué "Sí" y "En ocasiones" del 20.5 \% (17/83) al 21.7 \% (18/83) en San Quintín y 23.5 \% (8/34) en Mexicali; mientras que "No me he dado cuenta" y "No" del $28.9 \%$ (13/83) al $38.5 \%$ (32/83) para San Quintín y 50 \% (17/34) en Mexicali.

Tabla 4. Factores de la RA en actividades escolares. Fuente: elaboración propia.

\begin{tabular}{|c|c|c|c|c|c|c|c|c|c|c|c|c|c|c|}
\hline \multicolumn{15}{|c|}{ IV. Experiencia en lección de mapeo } \\
\hline & \multicolumn{2}{|c|}{$\begin{array}{c}\text { II.1. } \\
\text { Prevención }\end{array}$} & \multicolumn{4}{|c|}{ II.2. Interactúa con NEE } & \multicolumn{4}{|c|}{ IV.3 Reconocimiento marcador } & \multicolumn{4}{|c|}{$\begin{array}{l}\text { IV.4 Opción preferente } \\
\text { reconocimiento RA }\end{array}$} \\
\hline & $\begin{array}{l}\text { Muy } \\
\text { Útil }\end{array}$ & Útil & Sí & $\begin{array}{l}\text { En } \\
\text { ocasio- } \\
\text { nes }\end{array}$ & $\begin{array}{l}\text { No lo } \\
\text { he } \\
\text { notado }\end{array}$ & No & $1-3 \mathrm{~s}$ & $4-6 \mathrm{~s}$ & $7-10 \mathrm{~s}$ & $\begin{array}{c}\text { Más de } \\
11 \mathrm{~s}\end{array}$ & $\begin{array}{l}\text { Recono } \\
\text { cimien } \\
\text { to }\end{array}$ & $\begin{array}{c}\text { Audio } \\
\text { video }\end{array}$ & $\begin{array}{l}\text { Ima- } \\
\text { gen 3D }\end{array}$ & $\begin{array}{c}\text { Ima- } \\
\text { gen de } \\
\text { video } \\
\text { sobre- } \\
\text { puesto }\end{array}$ \\
\hline $\begin{array}{l}\text { Grupo } 1- \\
\text { rural (Vicente } \\
\text { Gro. 33/34) }\end{array}$ & 9 & 22 & 3 & 11 & 7 & 12 & 5 & 11 & 7 & 9 & 3 & 3 & 24 & 3 \\
\hline $\begin{array}{l}\text { Grupo } 2- \\
\text { rural (Vicente } \\
\text { Gro. 20/32) }\end{array}$ & 6 & 13 & 8 & 4 & 2 & 6 & 3 & 9 & 4 & 4 & 0 & 3 & 15 & 1 \\
\hline $\begin{array}{l}\text { Grupo } 3- \\
\text { rural (Ejido } \\
\text { Padre Kino } \\
28 / 40 \text { ) }\end{array}$ & 14 & 11 & 6 & 3 & 4 & 14 & 9 & 7 & 6 & 5 & 3 & 3 & 18 & 3 \\
\hline $\begin{array}{l}\text { Grupo } 4- \\
\text { urbana } \\
\text { (Mexicali } \\
34 / 36 \text { ) }\end{array}$ & 15 & 10 & 4 & 4 & 11 & 6 & 3 & 7 & 7 & 8 & 2 & 3 & 16 & 9 \\
\hline
\end{tabular}

\subsection{Percepción sobre nivel de complejidad y tiempos de reconocimiento por estudiantes}

En la columna IV.2 Complejidad, se puede observar que les resultó Fácil o Muy fácil, pero sólo en el Grupo 4 de la Escuela C en Mexicali, a 9 de 34 (26 \%) les resultó difícil la actividad. En el tiempo de reconocimiento los cuatro grupos tuvieron un tiempo mayor de 4 segundos, quedando de la siguiente manera: $81.82 \%, 85 \%, 64.24 \%, 64.70 \%$, respectivamente del grupo 1 al grupo 4. Finalmente, en la columna referente al $I V .4$ Opción preferente de $R A$, la mayoría optó por Imagen 3D virtual, con $70.58 \%, 75 \%, 64.28 \%$ y $47 \%$, respectivamente.

\subsection{Opinión de los maestros}

Por último, se cuestionó a los maestros voluntarios sobre distintas posturas de los alumnos cuando realizaron la actividad. En la Tabla 5 se pueden analizar para consideración las respuestas de los docentes; en el campo VIII. 
Tabla 5. Opinión de los maestros sobre actividad educativa. Fuente: elaboración propia.

\begin{tabular}{|c|c|c|c|c|}
\hline \multicolumn{5}{|c|}{ VIII.1 Preparación del contexto áulico } \\
\hline & \multicolumn{2}{|c|}{ Adecuado } & \multicolumn{2}{|c|}{ Inadecuado } \\
\hline \multirow[t]{2}{*}{ Tiempo de instrucción } & \multicolumn{2}{|c|}{$\mathrm{A}, \mathrm{B}$ y $\mathrm{C}^{*}$} & \multicolumn{2}{|c|}{. } \\
\hline & $\begin{array}{c}\text { Completamente } \\
\text { de acuerdo }\end{array}$ & De acuerdo & En desacuerdo & $\begin{array}{c}\text { Completamente } \\
\text { en desacuerdo }\end{array}$ \\
\hline Información suficiente y adecuada & A y B & $\mathrm{C}$ & - & - \\
\hline Material impreso adecuado & $\mathrm{A}, \mathrm{B}$ y C & - & - & - \\
\hline Dominio conceptual del facilitador & $\mathrm{A}, \mathrm{B}$ y $\mathrm{C}$ & - & - & - \\
\hline \multicolumn{5}{|c|}{ VIII.2 Actitud al uso de TIC en procesos de enseñanza-aprendizaje } \\
\hline & $\begin{array}{c}\text { Completamente } \\
\text { de acuerdo }\end{array}$ & De acuerdo & En desacuerdo & $\begin{array}{c}\text { Completamente } \\
\text { en desacuerdo }\end{array}$ \\
\hline TIC + celular apoya práctica docente & $\mathrm{A}, \mathrm{B}$ y $\mathrm{C}$ & - & - & - \\
\hline Actividad con RA fue un distractor para alumnos & - & - & - & $\mathrm{A}, \mathrm{B}$ y $\mathrm{C}$ \\
\hline \multicolumn{5}{|c|}{ IX.1 Aspectos individuales y en equipo } \\
\hline & $\begin{array}{c}\text { Completamente } \\
\text { de acuerdo }\end{array}$ & De acuerdo & En desacuerdo & $\begin{array}{c}\text { Completamente } \\
\text { en desacuerdo }\end{array}$ \\
\hline Motivación al diseñar mapa con RA & $\mathrm{A}, \mathrm{B}$ y $\mathrm{C}$ & - & - & - \\
\hline Fomentó participación la actividad & $\mathrm{A}, \mathrm{B}$ y $\mathrm{C}$ & - & - & - \\
\hline Actividad indujo hacia prevención y organización & A y B & $\mathrm{C}$ & - & - \\
\hline Actividad fomentó el trabajo autónomo. & A, B y C & - & - & - \\
\hline $\begin{array}{l}\text { Seguridad en estudiantes al responder } \\
\text { preguntas }\end{array}$ & $\mathrm{A}, \mathrm{B}$ y $\mathrm{C}$ & - & - & - \\
\hline \multicolumn{5}{|c|}{ IX.2 Formación y valores } \\
\hline & $\begin{array}{c}\text { Completamente } \\
\text { de acuerdo }\end{array}$ & De acuerdo & En desacuerdo & $\begin{array}{c}\text { Completamente } \\
\text { en desacuerdo }\end{array}$ \\
\hline Fomentó equidad y diversidad hacia NEE & $\mathrm{A}, \mathrm{B}$ y $\mathrm{C}$ & - & - & - \\
\hline Reafirma valores y conceptos preventivos & $\mathrm{A}, \mathrm{B}$ y $\mathrm{C}$ & - & - & - \\
\hline $\begin{array}{l}\text { RA medio tecnológico para potenciar el } \\
\text { aprendizaje }\end{array}$ & A, B y C & - & - & - \\
\hline $\begin{array}{l}\text { El ambiente fomentó la adquisición de } \\
\text { conocimientos }\end{array}$ & $\mathrm{A}, \mathrm{B}$ y $\mathrm{C}$ & - & - & - \\
\hline \multicolumn{5}{|c|}{ IX.3 Navegabilidad y uso del ambiente de aprendizaje } \\
\hline & $\begin{array}{c}\text { Completamente } \\
\text { de acuerdo }\end{array}$ & De acuerdo & En desacuerdo & $\begin{array}{l}\text { Completamente } \\
\text { en desacuerdo }\end{array}$ \\
\hline El grado de dificultad en la actividad es bajo & $\mathrm{A}, \mathrm{B}$ y $\mathrm{C}$ & - & - & - \\
\hline $\begin{array}{l}\text { Ambiente educativo con marcadores es fácil de } \\
\text { usar }\end{array}$ & B y C & $\mathrm{A}$ & & \\
\hline $\begin{array}{l}\text { La actividad de RA resultó atractiva. } \\
\text { visualmente }\end{array}$ & A, B y C & - & - & - \\
\hline
\end{tabular}

*Las opciones A, B y C se refieren al Docente A, Docente B y Docente C, respectivamente.

1) Preparación del contexto áulico, los docentes estuvieron" Completamente de acuerdo" en cuanto a: 'Material impreso adecuado' y 'Dominio conceptual del facilitador'; en 'Información suficiente y adecuada', uno se mostró "De acuerdo" y los otros dos "Completamente de acuerdo". En cuanto a VIII. 2) sobre Actitud al uso de TIC en procesos de enseñanzaaprendizaje, coincidieron en que usar TIC y celular apoya la práctica docente, pero que el uso de RA no fue considerado como un distractor significativo para los estudiantes; en IX.1 Aspectos individuales y de equipo, coincidieron en que hubo 'Motivación', 'Participación', 'Fomento del trabajo autónomo' y 'Seguridad al contestar preguntas'; referente a IX.2 Formación y valores: coincidieron en la alternativa "Completamente de acuerdo" en que "Fomentó equidad y diversidad hacia NEE", "Reafirma valores y conceptos preventivos", "RA 
medio tecnológico para potenciar el aprendizaje" y "El ambiente fomentó la adquisición de conocimientos". Referente al IX. 3) Navegabilidad y uso del entorno de aprendizaje, los docentes consideraron que fue sencillo y atractivo visualmente, pero sólo un maestro estuvo "De acuerdo" sobre la facilidad de uso y los otros dos estuvieron "Completamente de acuerdo".

\section{DISCUSIONES}

La RA, articulada en este estudio con el PBL, permitió a los estudiantes percibir en un entorno real elementos aumentados en un contexto educativo con fines formativos [23]. La actividad del acomodo de mobiliario indica un tipo de actividad que permite desarrollar aspectos críticos individuales para ser discutidos en grupos e identificar posibles anomalías y áreas de oportunidad [4]. En esta investigación se evidenció, por parte de los estudiantes y maestros involucrados, que el uso de RA y PBL durante la actividad didáctica proporciona una experiencia enriquecedora e interesante para los estudiantes al utilizar dispositivos móviles y elementos kinestésicos tradicionales [24].

Es importante hacer notar que durante la implementación se identificaron características de aspectos técnicos, infraestructurales, sociales y humanos propios de las comunidades rurales, las cuales propiciaron modificaciones en la actividad didáctica planeada inicialmente.

El modelo MRAE construido facilitó diseñar y modificar la actividad didáctica, ya que es flexible y propone alternativas de sustitución en cada uno de sus categorías, permitiendo potenciar el aprendizaje con el uso de tecnologías emergentes [9], especialmente en comunidades rurales, en zonas de difícil acceso, o aisladas como característica común al centro y sur de Baja California [25]. Por ejemplo, debido a las limitaciones identificadas por el levantamiento diagnóstico, en las áreas de estudio rurales indicaron una deficiente cobertura de internet asociada a una intermitencia de la señal; estas restricciones se pudieron identificar con el instrumento diagnóstico para realizar adecuaciones y/o cambios previos a la actividad de campo.

Resultó de gran importancia realizar un análisis contextual inicial de las características de los servicios de comunicación, de la infraestructura y de las características propias de la comunidad estudiantil, considerando aspectos sociales como lo son el sector dentro de las actividades económicas en las que se desempeñan los padres o el acceso a equipo de cómputo o dispositivos móviles y la conectividad a internet en casa o en la escuela, resultando esta última una limitante. Esta información permitió contextualizar mejor el escenario sobre la disponibilidad de celulares, el tipo y modelo de sistema operativo, las alternativas de red disponibles, así como la experiencia previa en actividades educativas; los datos recabados demostraron poca disponibilidad de dispositivos móviles en Vicente Guerrero y Ejido Padre Kino, y menor experiencia con software o tecnología educativa en estas dos escuelas comparadas con el entorno urbano.

En general, los estudiantes y maestros externaron que es una manera creativa y divertida de abordar la educación, lo cual generó una mayor aportación de opiniones en la lluvia de ideas para la distribución de un aula de clases. La aplicación de RA en el salón de clases generó gran curiosidad en alumnos y maestros, además que se puede implementar en distintas asignaturas o temáticas de clases [3]. Comparando las opiniones reflejadas por estudiantes en el instrumento de percepción y las respuestas abiertas de los maestros, es posible hacer una inferencia en que la experimentación con RA motiva e incentiva la colaboración del estudiante, en las etapas que se abordaron durante la actividad didáctica [2], y también facilita el aprendizaje por descubrimiento y a los docentes a realizar trabajos de tipo kinestésico o de campo [7]. 


\section{CONCLUSIONES}

La elaboración de la propuesta didáctica con RA en escuelas públicas tuvo que ser adecuada a las características y situaciones infraestructurales que se presentaron en las zonas rurales de Vicente Guerrero y Ejido Padre Kino; no obstante las ventajas que arrojan distintos estudios científicos sobre implementaciones de realidad aumentada (ver Tabla 1), se experimentaron los efectos positivos que se proponen en la tabla por estudiantes y maestros que participaron en las actividades didácticas realizadas. Asimismo, los resultados en las opiniones proporcionadas por estudiantes y maestros son muy semejantes, tanto en la zona rural donde se implementó, como en la zona urbana; es decir que se pueden esperar la misma dinámica y resultados a pesar del grado de marginación siempre y cuando se validen las condiciones mínimas de factibilidad contenidas en el instrumento diagnóstico.

El efecto obtenido de incluir la metodología del aprendizaje basado en problemas indujo a los estudiantes a ser sujetos activos en la solución de estos, siendo conscientes de su participación, con orientación a seguir valores preventivos e incluyentes. En la opinión de los estudiantes (ver Tabla 4), estuvieron de acuerdo que la actividad "Indujo hacia una conciencia de prevención", además de "Fomentar valores de equidad y diversidad tomando en cuenta estudiantes con necesidades especiales (NEE)".

En opinión de los maestros voluntarios sobre la actividad de RA con PBL, externaron que es constructiva porque existe "Motivación al diseñar mapa con RA", orientando hacia los intereses del alumno porque "Fomentó el trabajo autónomo", además que contribuye a la formación de estudiantes críticos y reflexivos, puesto que se observó "Seguridad en los estudiantes al responder preguntas" de tipo oral durante la fase de retroalimentación", en los campos de "Fomentar la participación" e "Indujo hacia la prevención y organización" (Ver Tabla 5); de igual forma, mostraron interés por un menú o portafolio didáctico con RA para ser más interactivas, participativas y/o ampliar la variedad de estrategias educativas con tecnologías emergentes.

Sobre aspectos técnicos y operativos, el grado de preparación y dominio de la tecnología no fue muy complejo según las opiniones externadas por estudiantes y maestros, y permite también que se realice con equipo móvil como celulares o tabletas; una vez desarrollada la planeación didáctica con RA, se puede compartir con estudiantes y maestros para su ejecución con una guía de acompañamiento que facilite el desarrollo de cada etapa de implementación.

Este tipo de proyectos beneficia a aquellas escuelas urbanas cuyo acceso a equipos de cómputo es limitado o que se encuentran en una comunidad rural con restricciones técnicas de distinta índole.

Los costos asociados a la implementación son bajos, ya que se utilizan los celulares con los que cuentan los estudiantes, simplemente necesitan descargar la aplicación que en este caso fue de tipo Android en su celular, además de equipo de papelería ordinario, pero eso depende de la planeación y alcance en los aprendizajes esperados de la dinámica. La facilitación o instrucción para los maestros para que pudieran acompañar las actividades les pareció sencillo y amigable, incluso se mostraron interesados en replicar esta actividad con mayor frecuencia por su accesibilidad.

\section{RECOMENDACIONES}

Se considera que el interés mostrado por estudiantes y maestros hacia la actividad con RA presenta áreas de oportunidad para materias que se dificultan a estudiantes como 
Matemáticas, Química e Inglés en estudiantes de nivel básico en secundaria y nivel medio superior [2].

El efecto esperado es incentivar y redirigir actividades educativas hacia el uso del celular, aprovechando las capacidades técnicas, flexibilidad en el uso, actualizaciones tecnológicas y creciente disponibilidad [26].

El levantamiento diagnóstico y el de percepción de la actividad, propone una referencia para suplir o complementar actividades educativas con software educativo, facilitando el uso de dispositivos móviles en el aula y dejen de considerarse como un obstáculo o desviación de la atención.

El trabajo realizado demuestra la factibilidad del uso de RA con dispositivos móviles como alternativa significativa entre el modelo de enseñanza tradicional y el asistido por computadora en medios audiovisuales para ser empleadas en áreas urbanas y rurales con un grado importante de marginación. Las modificaciones y adecuaciones realizadas en sitio fueron hechas debido a las carencias técnicas e infraestructurales propias de una comunidad rural y fue debido a que esas adecuaciones responden al contexto real obtenido a través del levantamiento diagnóstico, que se pudo realizar la actividad con éxito. Al adecuar la metodología de intervención acorde al contexto es posible impactar en la búsqueda de la disminución de la brecha de aprendizaje entre zonas rurales y urbanas, mostrada por los resultados de la prueba estandarizada Planea [16]. Esta brecha puede ser suavizada al aprovechar las tecnologías emergentes y software alternativo en equipos móviles, como la aplicación de RA, para emplearse de manera exitosa en zonas rurales o de alta marginación que carecen de equipos de cómputo, cobertura de red nula o intermitente, con efecto directo en los niveles de aprendizaje de los estudiantes.

La tendencia natural de RA, en el campo educativo, es abordar paulatinamente los demás sentidos, aparte del visual y auditivo, siguiendo por el tacto y el olfato; el reto es generarlo a costos asequibles para países en vías de desarrollo y analizar el impacto que tiene aumentar otros sentidos, por lo cual se prevé una creciente demanda en el campo educativo en los próximos años [24].

\section{AGRADECIMIENTOS}

Se agradece al organismo público Consejo Nacional de Ciencia y Tecnología por el apoyo brindado a este trabajo a través de la beca número (CVU/Becario): 475134/583049, consistente en apoyo económico para gastos personales y costos académicos relacionados al curso del doctorado. Se agradece también a la Universidad Autónoma de Baja California, en especial al Instituto de Investigación y Posgrado de la misma universidad, por haber facilitado sus instalaciones y equipo de cómputo en la documentación, revisión y análisis del proyecto.

\section{CONFLICTO DE INTERÉS}

Los autores manifiestan que no existe ningún conflicto de interés, ya sea financiero, profesional o personal que pudiera surgir de la publicación del presente artículo, ya que el financiamiento principal de este trabajo proviene de una institución pública sin fines de lucro (Conacyt). 


\section{CONTRIBUCIÓN DE LOS AUTORES}

Juan Gabriel López-Hernández: contribuyó compartiendo los elementos desarrollados durante el estudio del doctorado. Conceptualización, diseño y desarrollo del artículo.

Gabriel Alejandro López-Morteo: revisión y edición de los distintos capítulos y secciones de la tesis. Conceptualización, diseño y desarrollo del artículo.

Araceli Justo-López: revisión y edición de los distintos capítulos y secciones de la tesis. Modificaciones y recomendaciones en el establecimiento de la metodología, revisión y edición de conceptos y contenidos del artículo.

\section{REFERENCIAS}

[1] I. Radu, "Augmented Reality in Education: A Meta-review and Cross-media Analysis", Pers. Ubiquitous Comput., vol. 18, no. 6, pp. 1533-1543, Ago. 2014. http://dx.doi.org/10.1007/s00779-013-0747-y

[2] G. Gómez García; C. Rodríguez Jiménez; J. A. Marín, "La trascendencia de la Realidad Aumentada en la motivación estudiantil. Una revisión sistemática y meta-análisis”, Alteridad, vol. 15, no. 1, pp. 36-46, Ene. 2020. https://doi.org/10.17163/alt.v15n1.2020.03

[3] P. Sommerauer; O. Müller, "Augmented reality for teaching and learning-a literature review on theoretical and empirical foundations", Twenty-Sixth European Conference on Information Systems, Portsmouth, 2018. $\underline{\mathrm{URL}}$

[4] J. Cabero Almenara; B. Fernández Robles, "Las tecnologías digitales emergentes entran en la Universidad: RA y RV” RIED. Revista Iberoamericana De Educación a Distancia, vol. 21, no. 2, pp. 119-138, Jul. 2018. http://dx.doi.org/10.5944/ried.21.2.20094

[5] F. Sarracino, “'Mejora la realidad aumentada el aprendizaje de los alumnos? una propuesta de experiencia de museo aumentado", Profr. Rev. Curric. Form. Profr., vol. 18, no. 3, Sep. 2014. URL

[6] R. Hidalgo Hernández, “¿El uso del celular, un problema para el profesor en el aula o un medio de comunicación convertido en medio de enseñanza?”, Educación Médica Superior, vol. 29, no. 4, pp. 682-684, Oct. 2015. http://www.ems.sld.cu/index.php/ems/article/view/768

[7] G. Lorenzo Lledó; C. Scagliarini Galiano, "Revisión bibliométrica sobre la realidad aumentada en Educación", Rev. Gen. Inf. Doc., vol. 28, no. 1, pp. 45- 60, 2018. http://dx.doi.org/10.5209/RGID.60805

[8] N. M. Moreno Martínez; J. J. Leiva Olivencia, "Experiencias formativas de uso didáctico de la realidad aumentada con alumnado del grado de educación primaria en la Universidad de Málaga”, Edmetic Rev. Educ. Mediática TIC, vol. 6, no. 1, pp. 81-104, 2017. https://org.doi/10.21071/edmetic.v6i1.5809

[9] M. Prieto; S. Pech, La tecnología como instrumento para potenciar el aprendizaje. Comunidad Internacional para el Avance de la Tecnología en el Aprendizaje CIATA.org, Ciudad de México, 2016. URL

[10] T. Caudell; D. Mizell, "Augmented reality: An application of heads-up display technology to manual manufacturing processes", Proceedings of the Twenty-Fifth Hawaii International Conference on System Sciences, Kauai, 1992, pp. 7-10. https://org.doi/10.1109/HICSS.1992.183317

[11] P. Milgram; H. Takemura; A. Utsumi; F. Kishino, "Augmented reality: a class of displays on the realityvirtuality continuum", Proceedings Telemanipulator and Telepresence Technologies, vol. 2351, Dec.1995. https://org.doi/10.1117/12.197321

[12] A. de J. Ángeles Villeda, "Aprendizaje Basado en Problemas (ABP)", Bol. Científico Las Cienc. Económico Adm. ICEA, vol. 8, no. 15, Dic. 2019. https://doi.org/10.29057/icea.v8i15.4709

[13] "Vicente Guerrero", Nuestro México, 2015. URL

[14] EBCO, "Diagnóstico del contexto socio-demográfico del área de influencia del CIJ Mexicali", 2018. URL

[15] INEE, "Planea: una nueva generación de pruebas", 2015. URL

[16] INEE, "Planea Resultados nacionales 2017". ene. 2018. URL

[17] M. Crotty, The foundations of social research, meaning and perspective in the research process. University of London: SAGE, 1998. URL

[18] R. Hernández Sampieri; C. Fernández Collado; P. Baptista Lucio, Metodología de la Investigación (6ta edición). México, D.F.: McGRAW-HILL, 2014.

[19] A. Blázquez Sevilla., "Realidad aumentada en Educación", Gabinete de Tele-Educación del Vicerrectorado de Servicios Tecnológicos, 2017. URL

[20] S. Cuendet; Q. Bonnard; S. Do-Lenh; P. Dillenbourg, "Designing augmented reality for the classroom", Comput. Educ., vol. 68, pp. 557-569, Oct. 2013. https://doi.org/10.1016/j.compedu.2013.02.015 
[21] S. Gutiérrez; Á. Rodríguez, "Implementación de la metodología ABP (Aprendizaje Basado en Problemas) en la enseñanza de los materiales bituminosos para los estudiantes de Arquitectura de Interiores", Rev. Hist. Comun. Soc., vol. 19, pp. 413-425, Abr. 2014. https://doi.org/10.5209/rev HICS.2014.v19.45038

[22] R. Egea, "5 maneras diferentes de organizar el espacio en el aula", Con los pies en el aula, nov. 03. URL

[23] D. Travieso Valdés; T. Ortiz Cárdenas, "Aprendizaje basado en problemas y enseñanza por proyectos: alternativas diferentes para enseñar", Revista Cubana de Educación Superior, vol. 37, no. 1, pp. 125-133, Ene. 2018. URL

[24] CAICT, "Virtual Reality/Augmented Reality White Paper", China Academy of Information and Communications Technology (CAICT), Huawei Technologies Co, Dic. 2017. URL

[25] Sistema de Información Cultural SIC, "Directorio de los pueblos indígenas", 2019. URL

[26] INEGI, "Encuesta Nacional sobre Disponibilidad y Uso de Tecnologías de la Información en los Hogares", 2019. URL 